DE

\title{
Aspectual and idiomatic properties of the particle on in Late Modern Spoken English
}

\author{
Ljubica Leone \\ University of Salerno, Italy
}

\begin{abstract}
The present study focuses on the description of the semantic features of phrasal verbs (PVs) containing the particle on and specifically aims at analysing the historical development of aspectual and idiomatic combinations in Late Modern Spoken English. From a historical perspective, the "figurative usage" (Kennedy, 1920) of PVs is a very interesting feature because it is the product of historical processes resulting in the PVs as they are known in Present Day English (PDE). This study is a corpus-based investigation conducted on the Late Modern English-Old Bailey Corpus (LModE-OBC), a corpus that has been compiled by using texts from the Proceedings of the Old Bailey and annotated with the Visual Interactive Syntax Learning interface (VISL). The findings reveal that there was a general shift from spatial to aspectual meaning and a relative stability in the frequency of PVs in the time span 1750-1850. It can be assumed that PVs "have undergone a lexical development from compositional to noncompositional" (Thim, 2012, p. 12), a process that led PVs from being literal to figurative in meaning (Denison, 1981, p. 108; Claridge, 2000, p. 47) due to the semantic shift of particles from a directional to an aspectual connotation (Brinton and Akimoto, 1999, p. 8).
\end{abstract}

\section{Keywords}

on, phrasal verbs, Late Modern English, aspectual, POS tagging.

\section{Introduction}

The present study focuses on the description of PVs containing the adverbial particle on and specifically aims at analysing the historical development of aspectual and idiomatic combinations in Late Modern Spoken English.

PVs are generally defined as verbs composed of a verb and an adverbial particle (Biber, et al., 1999, p.403) that behave semantically and syntactically as a

\footnotetext{
'In the present research I describe PVs following the morphological approach, and thus the particle and the verb are a "complex head with the structure of [ $\mathrm{V} \mathrm{V}$ Part]" (Dehé, 2002, p. 7). This definition entails that the $V$ and the particle "form a unit" (Elenbaas, 2007, p. 38 ), and that they are one lexical item composed of two syntactic elements. I exclude the small clause interpretation (Aarts, 1989) and treat the $\mathrm{V}+$ particle as a unit which can be followed by a Noun Phrase (NP) in transitive patterns.
}

single lexical unit, which can often be replaced by a simple lexical verb' (Live, 1965, p. 428; Quirk, et al., 1985, p. 1162). Syntactically, in fact, due to the internal cohesion that the verbal and non-verbal element possesses, they can be treated as single "complex verbs formed in the lexicon" (Elenbaas, 2007, p. 38; cf. also Live, 1965, p. 428; Quirk, et al., 1985, p. 1162). These verbs can be used intransitively, ${ }^{2}$ that is in the pattern [Verb

I reserve the term "particle" for the adverbial particles of PVs, whereas the non-verbal element in prepositional verbs - that is verbs which select a Prepositional Phrase (PP) (Biber, et al., 1999, p. 405) will be simply named as "prepositions".

2 Verbs like to come in, to go on, to get up are considered as belonging to the category of PVs due to the internal cohesion that they possess. In this case, in fact, the particle is strictly connected with the preceding verb and syntactically it behaves as an adverbial particle. 
(V)]+Particle (Prt) (e.g. to come in, to get up), and, in transitive combinations, they occur in the shape of [ $\mathrm{V}+$ Particle]+Noun Phrase (NP) and V+NP+ Particle pattern (e.g. to try sth on vs. to try on sth), which is a distinctive feature of this verb group. ${ }^{3}$

Semantically, PVs may be highly polysemous and the meaning can range from purely literal to idiomatic (Kennedy, 1920; Bolinger, 1971; Fraser, 1974; Biber, et al., 1999; Claridge, 2000; Thim, 2012). The lexical verbs occurring in PVs are usually the most common lexical verbs (to go, to come, to put, etc.) and they are associated with physical movement and state, whereas the particles (on, down, up, in etc.) have spatial or locative meanings, but they can also exhibit an extended meaning making the construction in which they are involved idiomatic from a semantic point of view. According to König (1973, cited in Thim, 2012, pp. 13-20), PVs can be divided into two groups: compositional and non-compositional, with the former containing particles with directional and aspectual meaning and the latter containing verbs with idiomatic meaning.

From a historical perspective, their relative compositionality is a very interesting feature because such clines are the result of historical processes resulting in PVs as they are known in Present Day English (PDE).

In fact, many studies (Bolinger, 1971; Brinton, 1988; Claridge, 2000; Thim, 2012) have underlined that diachronically PVs "have undergone a lexical development from compositional to non-compositional" (Thim, 2012, p.12; cf. Denison, 1981, p. 108) due to the semantic shift of adverbial particles from a directional to a resultative connotation (Brinton and Akimoto, 1999, p. 8). Moreover, the particles, originally with spatial meaning, also came "to be grammaticalised as markers of verbal aspect" (Brinton and Traugott, 2005, p. 124) and some of them have undergone further changes leading to an increase in idiomaticity (Brinton and Akimoto, 1999, pp. 1-16), making the meaning of the construction in which they are involved completely non-compositional.

\footnotetext{
${ }^{3}$ Transitive PVs, unlike prepositional verbs (Biber, et al., 1999, p. 404), are characterized by two different syntactic patterns, that is one with the particle following the verb, as in (a), and another with the particle placed in end position following the NP, as in (b):
}

(a) V+Particle+NP (e.g. to have on a coat)
In this regard, since the early stages in the history of English, the emergence of new PVs as well as the semantic extension and the acquisition of aspectual and idiomatic connotations are strictly connected with the process of grammaticalization that first provoked the renewal of function of prepositions within the clause and then operated as a catalyst for their decategorialization to an adverbial particle status. Moreover, PVs were affected by systematic processes of internal restructuring that gradually gave rise to an extension in the semantic fields resulting in the demotivation of the original meaning and in the conventionalization of the aspectual force on a social level.

Considering that PVs were involved in changes leading towards the increase in idiomaticity from the shift from prefixes to post-verbal particle (Brinton, 1988, p.189) attested in the Old English period (Hiltunen, 1983), it is possible to hypothesize that the "subtle movement between literal and idiomatic" meanings (Denison, 1981, p. 108) also affected PVs in the following stages.

From this perspective, it is of great importance to outline the changes that occurred during the LModE period by trying to study the factors promoting the emergence of innovative meanings in PVs and the processes which caused an increase in idiomaticity and aspectuality.

In line with these considerations, in order to trace the diachronic development of aspectual and idiomatic meanings in PVs, a corpus, the Late Modern Spoken EnglishOld Bailey corpus (LModE-OBC), has been created and then automatically parsed using the VISL (Visual Interactive Syntax Learning) interface and its tools. Specifically, the corpus is a collection of texts (court records) from the Proceedings of the Old Bailey (http//www.oldbaileyonline.org), covering a period of 100 years, from 1750 to 1850 . According to Culpeper and Kytö (2010, pp. 16-18), the texts contained in the corpus belong to a group of speech-related genres and specifically to a speech-based group. In fact, they "are based on an actual 'real-life'

(b) $\mathrm{V}+\mathrm{NP}+\mathrm{Particle}$ (e.g. to have a coat on) The possibility of particle movement is considered a distinctive feature which allows PVs to be distinguished from prepositional verbs (Bolinger, 1971, pp. 10-11; Claridge, 2000, p. 52). 
speech event" (Culpeper and Kytö, 2010, p.17), and thus they can give us some insights into what the spoken language was like.

In this paper, a study focused on PVs containing the particle on will be carried out in order to discern the general trend in the semantic properties of these PVs and to analyse how these changes came about.

The paper is organized as follows: Section 1 provides a description of the semantic features of PVs in general; Section 2 describes the current study providing details of method and materials; and Section 3 contains a description of the results and considerations strictly related to our data.

\section{Theoretical background}

According to the classification proposed by König (1973, cited in Thim, 2012, pp. 1320 ), PVs can be divided into compositional and non-compositional verbs with the former containing verbs with directional and aspectual particles. While with noncompositional combinations it is not possible by definition to assign a specific meaning to the particle or to the verb (e.g. to give up, to set up, to point out), in compositional verbs there is no semantic opacity, and both the verb and the following particle contribute to the whole meaning of the verb+particle construction (e.g. to put on, to throw away, to carry on). In fact, the meaning can be deduced from its internal structure, since it can be readily understood both in verbs with aspectual and directional particles.

The literal combinations (e.g. to go back, to throw away, to bring in, to put on) containing a directional particle usually express motion or direction, and in intransitive constructions they can also be replaced by a directional prepositional phrase (PP). The aspectual PVs on the other hand denote both the aspectual meaning of completion/perfectivity (e.g. to break up, to catch up, to cut down) and of repetition/duration (e.g. to carry on) (Brinton and Traugott, 2005, p. 125), and the particle "may have an intensifying or aspectual force" (Quirk, et al., 1985, p. 1162) that affects the meaning of the lexical verb it is placed together with (Lipka, 1972).

\footnotetext{
${ }^{4}$ Aspect is related to "the speaker's viewpoint or perspective on a situation" and represents a grammatical category. Aktionsart is "an indication of
}

This means that PVs can show a different degree of opacity and that in many cases they possess an aspectual and idiomatic connotation (Brinton, 1988, p. 4). This difference in the semantic features of PVs can be related to their diachronic development that involves, as widely claimed in literature (Brinton and Akimoto, 1999; Brinton and Traugott, 2005; Rodríguez-Puente, 2012), grammaticalization sometimes also followed by the process of fossilization, i.e. the "loss of the ability to undergo the range of manipulation found with comparable free combinations" (Huddleston, et al., 2002 , p. 284). This explains why literal combinations are often considered the basis of idiomatic ones (Kennedy, 1920; Brinton, 1988; Brinton and Akimoto, 1999; Rodríguez-Puente, 2012) and underscores the point of studying them before their corresponding idiomatic patterns. In this regard, it is possible to assume that "literal phrasal verbs are the core from which figurative types are ultimately derived, and to which they are still connected" (Claridge, 2000, p.47).

More specifically, according to Brinton and Traugott (2005, p. 124), the aspectual PVs emerged as a consequence of a process of grammaticalization that provoked the decategorialization of the particles with spatial meaning which became "markers of verbal aspect". ${ }^{4}$ In fact, the particles underwent a "metonymic shift from directional to telic meaning" (Brinton and Traugott, 2005, p. 124; cf. Live, 1965, p. 437; Fraser, 1974, p. 6), adding a goal and an endpoint to the situation expressed by the preceding verb, and from locative meaning to aspectual connotation of duration/repetition (Curme, 1931, p. 379; Brinton, 1988, p. 167).

Moreover, many differences in terms of meaning and function can be found among the particles. The particles on and along, for example, do not show a telic aktionsart meaning as happens with up, down, through, out, away, over and off (Brinton, 1988, p. 235). Instead, on and along "can be seen as marking ingressive, continuative/iterative, egressive, or habitual aspect" (Brinton, 1988, p. 235) and behave similarly to other aspectualizers such as stop, begin and continue.

the intrinsic temporal qualities of a situation and is a lexical category" (Brinton, 1988, p. 3). 
In this regard, one of the most interesting particles characterized by an aspectual meaning is the particle on, as academics such as Poutsma (1926) have underlined in their works. In fact, this particle can be considered sui generis in that unlike with other particles it is also used in grammaticalized periphrastic expressions, as in to go on and to keep on, with a focus on the continuation and duration of the action.

On these bases, the intention is to study the changes in compositionality of PVs containing the particle on and to describe the processes involved in such a relevant aspect of the English verbal system, trying to point out the factors promoting the gradual increase in idiomaticity of PVs in the LModE era.

\section{The present study \\ 2.1 Motivation}

Many studies have been conducted on PVs (Bolinger, 1971; Fraser, 1974; Brinton, 1988; Cappelle, 2005; Elenbaas, 2007) and many of them also focus on the aspectual use of the particle on along with a description of its general semantic features (Kennedy, 1920; Poutsma, 1926; Bolinger, 1971; Brinton, 1988; Claridge, 2000). The reason for such great interest can be explained by considering the nature of this particle itself, because, in addition to being a preposition, it is also frequently used as an adverbial particle with locative, directional and aspectual meaning. More specifically, it can be used as an aspectual marker denoting a continuative/durative aspect (e.g. to carry on, to go on) and it can also occur with inceptive meaning in periphrastic constructions such as in the aspectual quasi-auxiliaries (or aspectualizers) (Brinton, 1988, p. 4) to go on and to keep on. In this regard, it should be observed that the semantic properties of the particle on are particularly interesting.

The first thing to observe is that this particle is extensively used conveying the meaning of expressing "motion through space" (Thim, 2012, p. 15) and it may mark direction with verbs expressing path, as in example (1):

(1) He then told me to go on to the Obelisk, in St. George's-fields, and I sat him down near the Elephant and Castle. (1790s)In

\footnotetext{
${ }^{5}$ Metonymization is a process operating in the context of grammaticalization which contributes to the development of aspectual forms (Brinton and Akimoto, 2005, p. 29; cf. Brinton, 1988, pp. 111-114).
}

addition, it may indicate a continuative/iterative aspect, and at the same time, in different contexts, it can mark "a situation which may otherwise have stopped as continuing" or the "situation as repeated" (Brinton, 1988, p. 175), as in example (2):

(2) Then you may go on swearing anything, you are a bad man. (1790s)

Considering that, from a diachronic perspective, aspectual PVs emerged as a consequence of a process of grammaticalization that led the particles to undergo a "metonymic shift" from a directional to a telic meaning (Brinton and Traugott, 2005, p. 124) but also to an aspectual connotation (Brinton, 1988), it is possible to suppose that the particle on was also involved in these changes. In fact, as has been proved in many studies (Brinton, 1988; Hiltunen, 1999; Thim, 2012; Rodríguez-Puente, 2013), the particle in PVs can be affected by a gradual increase in opacity in meaning over time, and then they may start to show different connotative properties resulting in semantic idiomaticity or simply extension in meaning.

It can be hypothesized that the same path affected the particle on during the LModE era and thus that it underwent a similar development as that of the previous stages (Denison, 1981; Brinton and Akimoto, 2005; Elenbaas, 2007). In this case, the particle could display an aspectual meaning and provide the verb which precedes it with an aspectual connotation. In particular, processes like grammaticalization and metonymization ${ }^{5}$ can lead to an increase in opaqueness and to the acquisition of an aspectual connotation in consequence of the demotivation at the semantic level and of the extension in the context of use of linguistic items.

This happens when, as a consequence of the grammaticalization of the particle and its reanalysis, the non-verbal element loses its independence and starts behaving as part of a single lexical item together with the preceding verb. Further changes promote the semantic extension in meaning and the shift from the literal meaning of 'status and position' to mark

Grammaticalization in fact entails semantic reanalysis which prompts changes in "interpretation, and meaning" (Hopper and Traugott, 2003, p.39). 
"the persistence" of an action (Brinton, 1988, p. 112).

\subsection{Aims}

Specifically, the aims are:

- to point out whether PVs containing the particle on were involved in the semantic shift from directional to aspectual meaning as proven with regard to the previous stages.

\subsection{The corpus}

The corpus used to carry out the present study is the Late Modern Spoken EnglishOld Bailey Corpus (LModE-OBC), a corpus collected by selecting texts from the
Proceedings of the Old Bailey ${ }^{6}$ (http://www.oldbaileyonline.org), which covers a period of 100 years from 1750 to 1850. The LModE-OBC is a monolingual diachronic corpus; the domain is public; the selected texts belong to the legal genre and specifically to the "legal-lay discourse" subgenre (Williams, 2013, p. 353; cf. Heffer, 2005). All the selected texts contain direct speech dating back to the years 1750-1850 and are similar in length. In fact, the LModE-OBC consists of ten subcorpora (one per decade) of 100,000 words each, and the whole corpus amounts to a total of $1,008,234$ words, as represented in Table 1 :

\begin{tabular}{|c|c|c|c|c|}
\hline \multirow{11}{*}{ LModE-OBC (1750-1850) } & & Time span & Tokens & \multirow{11}{*}{$1,008,234$ words } \\
\hline & Subc-1 & $1750-1759$ & 100.693 & \\
\hline & Subc-2 & $1760-1769$ & 100.840 & \\
\hline & Subc-3 & $1770-1779$ & 100.800 & \\
\hline & Subc-4 & $1780-1789$ & 100.762 & \\
\hline & Subc-5 & 1790-1799 & 100.888 & \\
\hline & Subc-6 & $1800-1809$ & 100.882 & \\
\hline & Subc-7 & $1810-1819$ & 100.799 & \\
\hline & Subc- 8 & $1820-1829$ & 100.815 & \\
\hline & Subc-9 & 1830-1839 & 100.847 & \\
\hline & Subc-10 & $1840-1849$ & 100.908 & \\
\hline
\end{tabular}

\section{Table 1: The LModE-OBC corpus}

- to identify the processes of change affecting the PVs containing on that caused the development of aspectual connotation.

Specifically, it provides speech-based texts (Biber, et al., 1998, p. 252) usually considered of great value for those interested in the development of English in a period predating the technology of audio recordings.

The main criteria used to select the texts to include in each decade were that the texts should:

1. Be in the form of monologue or dialogue;

2. Contain only direct speech;

3. Represent the language of the period from 1750-1850.

${ }^{6}$ The Proceedings of the Old Bailey are the source data of another important corpus, the Old Bailey corpus (http://www1.uni-giessen.de/oldbaileycorpus) covering the period from 1834 to 1913 and compiled
4. The corpus has also been automatically parsed by using the VISL (Visual Interactive Syntax Learning) interface, $^{7}$ a project developed at the Southern Denmark University covering 14 different languages (Bick, 2001).

\subsection{Method}

This study is a corpus-based investigation which involves both quantitative analysis and qualitative interpretation in the description of language usage.

In the present research, quantitative analysis consists of both descriptive and inferential statistics and makes use of Raw frequency $(R f)$ and Normalized frequency (Nf) (base of normalization 10,000 words), Percentages/Relative frequency and Percentage points, log-likelihood test (LL). Considering that the overall corpus numbers about $1,000,000$ words, this kind of analysis was considered very useful in

at the University of Giessen (Huber, 2007; Huber, et al., 2012).

${ }^{7}$ Available at http://www.beta.visl.sdu.dk/ 
the description and evaluation of the results.

A qualitative analysis of the findings followed quantitative counts.

\subsubsection{Procedure}

Specifically, the methodological characteristics of this study are: 1) the compilation and use of a corpus to provide a database for linguistic analysis; 2 ) the use of computer tools to annotate the corpus enabling a Part of Speech (POS) analysis; 3) the use of a concordancer to retrieve data; 4) the use of statistical techniques and the qualitative interpretation of the results.

After both compilation and annotation of the LModE-OBC corpus with the VISL parser, we selected the linguistic features to analyse, and we started the process of data retrieval using the ConcApp Concordancer, which allowed us to search for a single word and a POS tag in all the texts under investigation.

As for VISL, it is a parser based on the Constraint Grammar (CG) methodology (Karlsson, 1995) that contains many linguistic tools such as parsing and POS tagging. Its central principle is that it is focused on "surface structure (expressed as either dependency relations or syntactic tree structure) and the form function dichotomy" (Bick, 2001, p. 2). The parser adds a tag with upper case letters for each word token followed by "the -@ Symbol to introduce function tags, and arrow heads $(>,<)$ for head oriented dependency markers" (Bick, 2001, p. 2). In addition, VISL provides lemmatization, inflection and shows the dependency links within a sentence.

Table 2 shows a sample text taken from the annotated version of the LModE-OBC:

\begin{tabular}{|c|c|c|c|}
\hline POS & $\begin{array}{l}\text { Functional } \\
\text { categories }\end{array}$ & Definition & \\
\hline ADV & $@ A D V L$ & $\begin{array}{l}\text { Adjunct [free] } \\
\text { adverbial }\end{array}$ & $\begin{array}{c}\text { I [I] PERS 1S NOM @SUBJ }>\text { drove } \\
\text { [drive] }<\text { mV }>\text { V IMPF @FS-STA on } \\
\text { [on] ADV @ }<\text { ADVL to [to] PRP @A }< \\
\text { the [the] ART S/P @ }>\text { N sign [sign] N S } \\
\text { NOM @P }<\text { of [of] PRP @N }<\text { the } \\
\text { [the] ART S/P @ }>\text { N Cheshire Cheese } \\
\text { [Cheshire=Cheese] N S NOM @P }<\end{array}$ \\
\hline ADV & $@ M V$ & $\begin{array}{c}\text { Main- verb } \\
\text { attached particle }\end{array}$ & $\begin{array}{c}\text { [I] PERS 1S NOM @SUBJ }>\text { got } \\
\text { [get] }<\text { mV }>\text { V IMPF @FS-STA up } \\
\text { [up] ADV @MV }<\text {, [,] PU @PU and } \\
\text { [and] KC @CO put [put] <mV > V IMPF @FS- } \\
\text { STA on [on] ADV @MV }<\text { my [I] PERS 1S } \\
\text { GEN @>N cloathes [cloathe] N P } \\
\text { NOM @<ACC }\end{array}$ \\
\hline PRP & $@ A D V L$ & $\begin{array}{l}\text { Adjunct [free] } \\
\text { adverbial }\end{array}$ & $\begin{array}{c}\text { He [he] PERS MASC 3S } \\
\text { NOM @SUBJ }>\text { left[leave] }<\text { mV }>\text { V IMPF @FS- } \\
\text { STA me [I] PERS 1S ACC @<ACC, [,] PU @PU } \\
\text { to [to] INFM @INFM } \\
\text { go[go] }<\text { mV }>\text { V INF @ICL- }<\text { ADVL on } \\
\text { [on] PRP @ }<\text { ADVL this [this] INDP } \\
\text { S@P }<\text { errands [errand] N P NOM @ }<\text { ACC }\end{array}$ \\
\hline
\end{tabular}

Table 2: Sample text taken from the annotated version of the LModE-OBC

The extraction of syntactic constituents was carried out on the annotated version of the corpus.
The tags and the functional categories considered important in this research are represented in Table 3: 


\begin{tabular}{|l|l|l|}
\hline POS & $\begin{array}{l}\text { Functional } \\
\text { categories } \\
<\text { main } \\
\text { verb }>\end{array}$ & Definition \\
\hline ADV & @ADVL & $\begin{array}{l}\text { Adjunct } \\
\text { [free] } \\
\text { adverbial } \\
\text { Main- verb } \\
\text { attached } \\
\text { particle }\end{array}$ \\
\hline ADV & @MV< & $\begin{array}{l}\text { Adjunct } \\
\text { [free] } \\
\text { adverbial }\end{array}$ \\
\hline PRP & @ADVL & \\
\hline
\end{tabular}

Table 3: Some VISL tags considered useful for the present study.

Specifically, the tag selected to retrieve the data was $V$ (verb) when followed by both ADV (adverb) and PRP (preposition). Considering that the particles in PVs are often categorized under the tags ADV with $@ M V>$ function, but sometimes also as ADV or PRP functionally behaving as adverbial, @ADVL, a manual analysis has complemented the automatic one in order to reduce inaccuracy. This means that after the retrieval of all the occurrences of the $V$ followed by the tags ADV and PRP, only the instances characterized by the linguistic features typically associated with PVs were selected, and all the prepositional verbs were excluded from the analysis.

The features which were considered important in distinguishing PVs from prepositional verbs and free combinations are both structural and semantic. In the first case the main feature of PVs is the fact that they allow two basic patterns: one which is characterized by the particle placed before the Direct Object (DO) (continuous order), as in (a), and another pattern in which the DO precedes the particle (discontinuous order), as in (b):

(a) He threw away the stockings.

(b) He threw the stockings away.

This is a possibility which is not acceptable in the case of prepositional verbs, where the object must always follow the preposition. In fact, considering (c) and (d) below, only the first structure is grammatical, in contrast with the second pattern: (c) He told me he had $900 \mathrm{I}$. lay in Sir Daniel Lambert's hands, and insisted on my going there with him.

(d) He told me he had 900 I. lay in Sir Daniel Lambert's hands, and insisted my going there with him on.*

In addition, another important feature which is typically associated with phrasal verbs (Biber, et al., 1999, pp. 404-405) is that which is related to the semantic properties of the construction. In fact, PVs possess a specific feature, so-called "lexical integrity", and the possibility of being substituted with simple verbs (Biber, et al., 1999, p. 404).

In this study, the overall number of PVs selected on the basis of the procedure explained above amounts to 10,000 occurrences. However, considering the specific aim of the present study, this result was only used to define the number of aspectual PVs containing the particle on out of the total and to gain much more information on the significance of the results.

In addition to the LModE-OBC, to compare the findings with other texts of PDE the materials used belong to the Oxford English Dictionary (OED). ${ }^{8}$

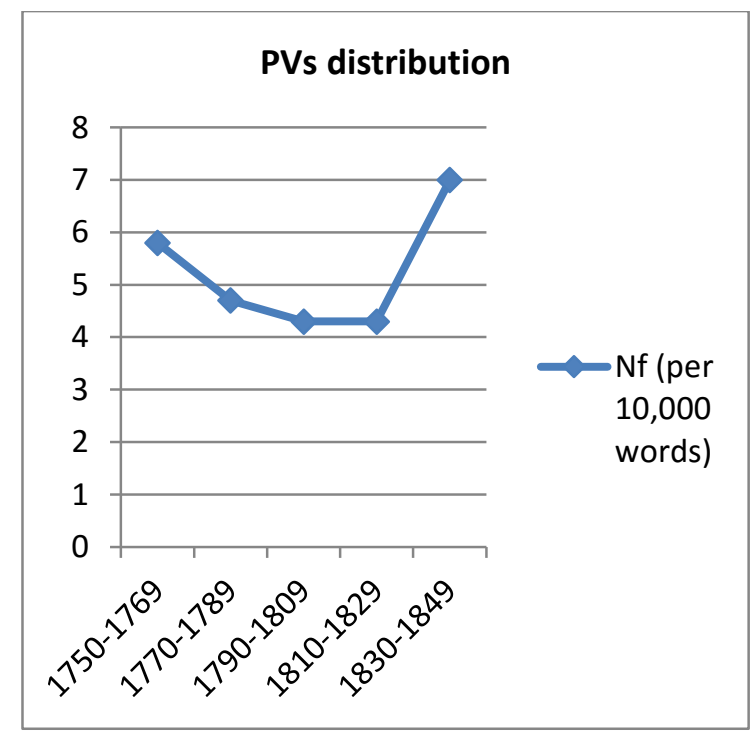

Figure 1: The general trend of the PVs which contain the particle on in the LModE-OBC (Normalized frequency per 10,000 words)

\footnotetext{
${ }^{8}$ http://www.oed.com
} 


\section{Results and discussion}

\subsection{Plotting the trend over time}

Analysing the distribution of PVs with on as represented in Figure 1 it is clear that they have not increased uniformly across the decades. Instead, they reach a peak towards the end of the years 1830-1849. There is a decline during the years 1750 1809 whereas a steady development can be found from 1810 onwards.

The lack of continuity in the rate can probably be related to the culture of correctness (Rydén, 1998, p. 227) and prescriptivism that characterized the language of that time (Tieken-Boon van Ostade, 2009, pp. 2-5), and this tendency may probably have limited the use of PVs containing the particle on but also PVs in general. The decline in use of PVs as found in the LModE-OBC is in line with the findings of other studies which report that the LModE period was characterized by a limited occurrence of these verbs (Spasov, 1966; Claridge, 2000; Wild, 2010; Rodríguez-Puente, 2013) when compared with previous stages. This limitation in use can be considered indicative of an ongoing process of innovation which affected the grammatical system of the time and at the same time the outcome of a renewal of interest in the language as a system (Crystal, 2010, pp. 78-79).

Looking at the lexical features of the PVs containing on as shown in Table 4 , it is possible to note that the most frequent verbs are to have on, to go on and to carry on, and this reveals a certain amount of stability in the use of these PVs:

\begin{tabular}{|c|c|c|c|c|}
\hline $1750 \mathrm{~s}$ & $1770 \mathrm{~s}$ & $1790 s$ & $1810 s$ & $1830 \mathrm{~s}$ \\
\hline $\begin{array}{c}\text { To have on } \\
\text { sth }\end{array}$ & $\begin{array}{c}\text { To have on } \\
\text { sth }\end{array}$ & $\begin{array}{c}\text { To have on } \\
\text { sth }\end{array}$ & $\begin{array}{c}\text { To have on } \\
\text { sth }\end{array}$ & To go on \\
\hline To go on & To go on & To go on & To go on & $\begin{array}{c}\text { To have on } \\
\text { sth }\end{array}$ \\
\hline $\begin{array}{l}\text { To carry on } \\
\text { sth/ } \\
\text { To put on } \\
\text { sth }^{9}\end{array}$ & $\begin{array}{l}\text { To put on } \\
\text { sth }\end{array}$ & $\begin{array}{c}\text { To carry on } \\
\text { sth }\end{array}$ & $\begin{array}{l}\text { To put on } \\
\text { sth }\end{array}$ & $\begin{array}{l}\text { To put on } \\
\text { sth }\end{array}$ \\
\hline To hold on & To come on & $\begin{array}{l}\text { To put on } \\
\text { sth }\end{array}$ & $\begin{array}{l}\text { To walk on/ } \\
\text { To get on }\end{array}$ & $\begin{array}{c}\text { To carry on } \\
\text { sth }\end{array}$ \\
\hline To drive on & To walk on & $\begin{array}{l}\text { To get on } \\
\text { sth/ } \\
\text { To try on } \\
\text { sth }\end{array}$ & $\begin{array}{l}\text { To carry on } \\
\text { sth/ } \\
\text { To come on }\end{array}$ & To move on \\
\hline
\end{tabular}

\section{Table 4: The most frequent verbs containing on}

The reason for this stability can be found in the fact that the texts analysed are narrative in form, and moreover contain a description of events and give details about what happened at a specific moment in time, with specific reference to a crime such as murder, robbery or cases of fraud. This may probably be the reason behind such a high frequency in the use of verbs such as

\footnotetext{
${ }^{9}$ To get on sth and to put on sth are two examples of PVs which can behave as prepositional verbs in other contexts of use. In particular, some combinations can "function as different structural categories in different contexts" (Biber, et al., 1999, pp. 405-406). In these cases the test of particle movement $(\S 1)$ is of great importance. In fact, the possibility of particle movement and semantic cohesion were the tests used to distinguish PVs from other verbs, such as prepositional verbs, which are in some cases similar in shape. Consider, for example, the verb to get on as represented in (a) and (b):
}

(a) I get on the jacket. (b) I get on the bus. to have on, with the sole meaning of 'to be wearing' (Collins COBUILD Phrasal verb dictionary), due to the fact that when talking about a crime the identification of the criminal through a description of what was being worn at that moment acquires relevance for forensic evidence to be collected. Similarly, the high number of instances of the verb to go on may be

\footnotetext{
The verb to get on is classified as a PV in the first case but not in the second one where it marks a PP with an adverbial function which does not allow constructions like that in (c) nor the substitution with a simple synonym verb, as (d):

(c) I get the bus on* (d) I go/ enter the bus*

In contrast, (a) can be rewritten as I get the jacket on, and as I wear the jacket. The particle movement and the possibility of substitution with a simple verb is the proof that (a) is a case of a PV rather than a prepositional verb (Biber, et al., 1999, p. 404).
} 
explained by considering the meaning of the verb itself in that it is used with the meaning of 'to go to another place', or 'to encourage somebody to do something' (Collins COBUILD Phrasal Verbs Dictionary). In fact, considering the communicative properties of the texts under analysis, the description of the scene of the crime together with a detailed account of actions and events are of great importance.

In general, the central issue is that of the presence of the same verbs in the top position, and this underscores that these kinds of verbs were moving towards stabilization in use, a step that acquires great importance especially in the development of new meanings and in the variation of the context of use.

\subsection{Frequency and use of the particle on with aspectual meaning}

The whole corpus does not present many instances of verbs containing the particle on, but this particle, despite its relatively low frequency, is very interesting in that it can provide information on the way the meaning of the base verb can acquire new connotative properties. In fact, the meaning of the particle contributes to the meaning of the whole combination. The resulting verb can thus display different semantic properties, and on the whole each one is characterized by a "core" meaning that links it with a single specific domain.

In this view, PVs containing on can be divided into two groups: activity and aspectual verbs. Following Biber et al.'s perspective (1999, pp. 360-428), PVs and more generally every lexical verb possess multiple meanings.

Table 5 shows the most frequent PVs containing on with aspectual meaning grouped together by semantic domain:

\begin{tabular}{|l|l|l|l|}
\hline Type & Verb & Rf & $\begin{array}{l}\text { Nf } \\
\text { (per 10,000 } \\
\text { words) }\end{array}$ \\
\hline $\begin{array}{l}\text { Activity } \\
\text { transitive }\end{array}$ & $\begin{array}{l}\text { To have on sth } \\
\text { To try on sth } \\
\text { To put on sth } \\
\text { To get on sth }\end{array}$ & 198 & 1.96 \\
\hline $\begin{array}{l}\text { Activity } \\
\text { intransitive }\end{array}$ & To come on & 71 & 0.08 \\
\hline $\begin{array}{l}\text { Aspectual } \\
\text { transitive }\end{array}$ & To carry on sth & 10 & 0.70 \\
& To go on sth & 34 & 0.09 \\
\hline & To keep on sth & 9 & 0.13 \\
Aspectual & To go on & 117 & 0.33 \\
intransitive & To drive on & 5 & 0.08 \\
& To pass on & 5 & 0.01 \\
& To move on & 6 & 1.16 \\
& To walk on & 15 & 0.04 \\
& To run on & 1 & 0.04 \\
\hline
\end{tabular}

Table 5: PVs containing the particle on with aspectual meaning

In the case of the activity verbs, it is possible to state that they denote actions and events whereas the aspectual ones convey information also on the state of the action or event, describing it as ingressive, continuative or egressive.

For example, to go on is specifically used as an exhortation to act, (3), or also to "mark continuation" (Biber, et al., 1999, p. 411 ) of an action taking a complement -ing or -to clause as its direct object, (4) and $(5)::^{10}$

${ }^{10}$ All the examples are taken from the LModE-OBC if not otherwise specified.
(3) "Go on, go on;" the prisoner then went on before me to the tail of the waggon, and attempted to take a box. (1810s)

--- Aspectual intransitive----

(4) When he returned to me he told me I might go on shipping, and pass the entries. (1830s)

--- Aspectual transitive----

(5) I got up at the same time in the morning as usual to dress my goods; I went on to work the servant came down stairs. (1810s)

--- Aspectual transitive---- 
These examples confirm that in the majority of cases the particle on can be considered synonymous with "onwards" (Kennedy, 1920, p. 21). This also suggests that, as expressed in (3)-(5), the intrinsic function of the particle under analysis is to contribute to the meaning of the preceding verb, adding the meaning of duration and continuity.

As represented in Table 5 above, among the transitive verbs and in addition to the verbs to carry on and to keep on there is also the verb to go on. This is not surprising if we consider that in PDE this is a verb frequently used to indicate the duration of an action with a -to infinitive and -ing clause as complement (Biber, et al., 1999, p. 411 ), together with to keep on. However, only a few instances can be found in the whole corpus, specifically four in the years 1750-1799, as in (6), and five in the years 1800-1850, as in (7)-(8):

(6) I went on hearing the conversation about a robbery I had committed. (1750s)

(7) The Defence then went on to state, at a considerable length, circumstances which appear in the following evidence. (1810s)

(8) hen you may go on swearing any thing, you are a bad man. (1790s)

Significantly, they show a syntactic behaviour similar to that found in PDE: two of these forms, (6) and (8), are syntactically composed of the base verb + ing-clause whereas the other one, as in (7), takes a toinfinitive clause as its direct object.

Furthermore, looking at the syntactic construction it is evident that the aspectual force of the particle can also be emphasized by the use of the following verb in the progressive form, as in (4) and (6), and this continuative and iterative aspect is linked to the syntactic restriction that does not allow any stative verbs to follow an aspectual particle such as on (Brinton, 1988, p. 175). In this regard, it is worth noting that on frequently occurs with a continuative aspect when it is preceded by durative verbs, as in the case of to go on and to keep on (Poutsma, 1926, p. 307).

As for the different use of transitive and intransitive patterns, in general, there is a tendency to use aspectual verbs in the intransitive form, as represented in Figure 2:

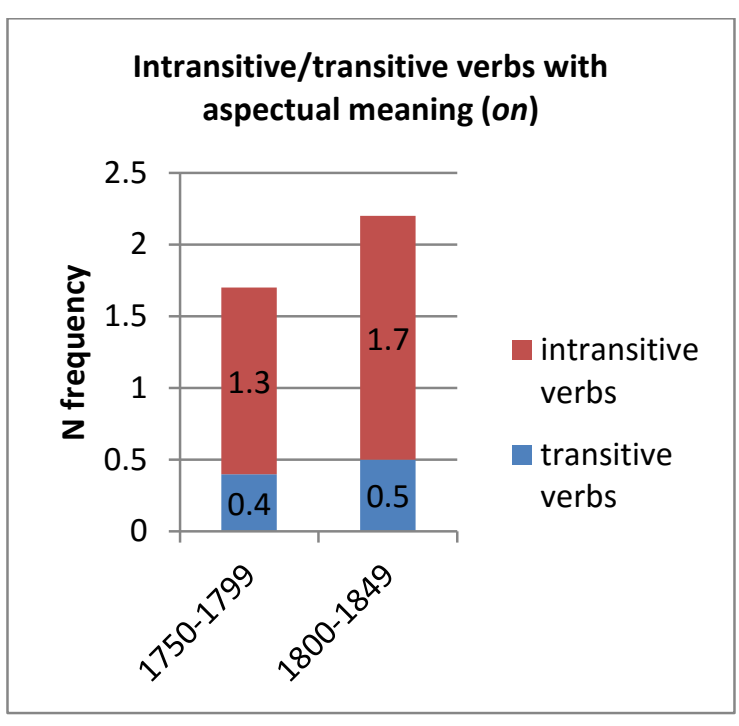

Figure 2: Intransitive and transitive verbs with an aspectual meaning ( $\mathrm{Nf}$ per 10,000 words).

In general, there is a strong preference and a steady increase in the use of the intransitive pattern in both the years 1750 1799 and 1800-1849, whereas the transitive pattern on the whole shows a tendency towards stability over time. This trend can be explained by the fact that only three types of transitive verbs occur in the corpus, specifically to carry on, to go on, and to keep on as represented in Table 6 below: 


\begin{tabular}{|l|l|l|l|}
\hline & $\begin{array}{l}1750-99 \\
(\mathrm{Nf})\end{array}$ & $\begin{array}{l}1800-49 \\
(\mathrm{Nf})\end{array}$ & $\begin{array}{l}\text { Change } \\
\text { in frequency } \\
\text { Diff (n/10,000) }\end{array}$ \\
\hline To carry on & 0.33 & 0.33 & $+/-0.00$ \\
\hline To go on & 0.07 & 0.09 & +0.02 \\
\hline To keep on & 0.02 & 0.04 & +0.02 \\
\hline
\end{tabular}

Table 6: Transitive verbs containing on with aspectual meaning.

As is evident by observing Figure 2, transitive verbs containing on are used only rarely in comparison with the intransitive patterns. In fact, these transitive verbs constitute only $25.5 \%$ of all occurrences of the verbs containing on in the years 1750 1799 and $28 \%$ in the years 1800-1849.

Analysis of the intransitive verbs shows that by comparing the verbs found in the years 1750-1799 and in the years 18001849 there are some PVs that are only found in the first case (e.g. to run on) whereas others are only attested from the 1830 s onwards (e.g. to move on).

In the following table, we consider in detail the most frequent aspectual intransitive PVs containing the particle on:

\begin{tabular}{|l|l|l|l|}
\hline & $1750-99$ & $1800-49$ & $\begin{array}{l}\text { Change in frequency } \\
\text { Diff }(\mathrm{n} / 10,000)\end{array}$ \\
\hline To drive on & 0.07 & 0.02 & -0.05 \\
\hline To go on & 1.00 & 1.32 & +0.32 \\
\hline To move on & 0.00 & 0.11 & +0.11 \\
\hline To pass on & 0.02 & 0.08 & +0.06 \\
\hline To run on & 0.02 & 0.00 & -0.02 \\
\hline To walk on & 0.16 & 0.14 & -0.02 \\
\hline & & & \\
\hline
\end{tabular}

Table 7: Aspectual intransitive PVs ( Nf per 10,000 words)

The first thing to note is that there is a relative stability in the use of the aspectual intransitive PVs. However, an interesting element is that a new aspectual verb emerges over time, namely to move on, and another increases in use, to go on.

\subsection{Semantic shift towards aspectual meaning}

The question that arises is whether this relative stability in lexical and syntactic features also characterized the semantics of the PVs containing on.

As for transitive verbs, with the exception of the instances of to go on, no relevant changes can be found. Both to carry on (the most frequent verb) and to keep on are used in the syntactic pattern as they are in PDE. In the 18th and 19th centuries, on the other hand, the semantic changes consisted of a simple extension in meaning and in the acquisition of new contexts of use, and in a few cases they resulted in the shift from a directional to aspectual connotation. In fact, as far as to carry on is concerned, there is a slight change in its semantic preference and an extension in its context of use.

Specifically, the combination to carry on is used with the meaning of 'to conduct, transact, pursue' (Cowie and Mackin, 1975) and often occurs with a NP denoting the kind of activity conducted, as in the examples below:

(9) My husband was a founder and brazier, but he is dead, and I carry on the business. (1750s)

(10) Mr. Coyde told me he would not let me have it. He said he did not understand carrying on any correspondence with Mr. Weeley in Newgate.(1750s)

(11) By whose expence is this prosecution carried on? (1790s)

(12) it was formerly occupied by Mr. Salkeld, who carried on the same trade; I have occupied it about four years and a half. (1810s) 
(13) I reside at Edmonton, and carry on business in London, as a stock-broker the prisoner was in my service about seventeen months. (1830s)

These examples suggest that while in the years 1750-1799 to carry on can be used mainly with words such as correspondence, as in (10), and prosecution, as in (11), along with a wellestablished use in collocation with the word business (9), from 1810 onwards it is almost exclusively followed by trade (12) and business (13). In fact, according to the Oxford English Dictionary (OED), this verb denotes the meaning of 'to practise continuously' and appears as a collocation of business from the year 1644, as reported in the following example, and this confirms that the aspectual connotation has been a well-established feature of this particle since the earlier stages:

(14) Carrying on his business with so much success. (OED-1644)

Consequently, it is possible to assume that the use of to carry on with words referring to the activity of buying, selling or supplying goods goes back to the early periods of the history of English and that it became stable through the LModE era. Moreover, these findings are also completely supported by what Claridge (2000, p. 242) states in her work on multiword verbs when discussing the aspectual features of the particle on in the Early Modern English period (EME). In fact, in line with our results, she reports that the word trade, for example, is the lexical item that this kind of verb usually collocates with (Claridge, 2000, p. 242), displaying a pattern of use which is also attested in PDE.

However, turning to the specific case of the Late Modern period, it should be noted that despite showing a kind of continuity with the Early Modern period, to carry on underwent a change in its meaning and specifically an increase in abstractness and in the number of collocates. As for (9), in particular, to carry on was used in a specific way to indicate the duration of the prosecution and this case is not only important to prove the emergence of a new set of collocates in the LModE period but it can also be seen as the starting point of an ongoing process of change that resulted in an extension in the meaning of the verb to carry on itself. In fact, this innovative use is attested in the OED, which confirms that the occurrence of the verb to carry on with the new meaning of 'to conduct', 'to manage', 'to work at', 'to prosecute' in collocation specifically with the word trial first appeared in 1810, as in (15):

(15) His trial must be carried on in open day. (OED - 1810)

Interestingly, this use was also found with the verb to conduct, as in (16), which became more frequently used with this meaning with the word prosecution, especially in the 1830s:

(16) I believe this is the first time I ever made that statement I never made it to the gentleman conducting this prosecution. (1830s)

These examples make clear that to carry on was increasingly used followed by different collocates and that the occurrence in various contexts of use resulted in an extension in the meaning and in the reinforcement of the aspectual force.

As for the intransitive verbs, one of the most interesting PVs is to go on, which increases in use but did not undergo any change in meaning. It is used with both spatio-directional meaning, that is in contexts in which it can be replaced by a prepositional phrase and the aspectual meaning expressing the duration/continuation of an event. It is interesting to note that this verb continued to be used with the meaning of 'to proceed, continue, progress' (OED), contributing to the reinforcement of the aspectual connotation that first appeared in the 16th century, as in (17), and that was established in the 18 th century, as in (18):

(17) The losses and detriments thereof partly are, and more wil be irrecouerable and aboue all recompense, if it go on vnpreuented in time. (OED-1572)

(18) Go on, then, I say; banish the occupants or owners, or kill them,...and take their land and property as spoil. (OED 1844 )

In fact, considering the distributional properties of this verb in the LModE-OBC, there is an increase in use from the $1800 \mathrm{~s}$ onwards. To go on in fact represents $62.8 \%$ and $66 \%$ out of all instances of the verbs with aspectual meaning containing on, as 
represented in Table 8 , and increased by +3.2 percentage points from the years 1750-1799 to 1800-1849:

\begin{tabular}{|l|l|l|l|l|l|}
\hline & $\begin{array}{l}\text { Raw } \\
\text { Frequency } \\
(R f)\end{array}$ & $\begin{array}{l}\text { Nf } \\
\text { (per 10,000 } \\
\text { words })\end{array}$ & $\begin{array}{l}\text { Relative } \\
\text { frequency } \\
(R f)\end{array}$ & $\%$ & Percentage points \\
\hline $\begin{array}{l}1750- \\
1799\end{array}$ & 54 & 1.07 & 0.62 & 62.8 & +3.2 \\
\hline $\begin{array}{l}1800- \\
1849\end{array}$ & 72 & 1.42 & 0.66 & 66.0 & \\
\hline
\end{tabular}

Table 8: Difference in the rate of use of the verb to go on.

Nevertheless, despite this increase in use the log-likelihood (LL) test $(p<0.05)$ reveals that it is not statistically significant:

\section{LL $\mathrm{p}<0.05 \quad 5 \%$ level \\ 2.57 not significant}

Functionally, to go on is used as an exclamatory exhortation and also to mark continuation of some general actions as in (19) and (20) respectively:

(19) "Send them on" upon that one of them said, "Hit them with your carbine" I could not see who it was said that the prisoner upon that said, "Go on," in a very imperative tone. (1830s)

(20) For some days the thing went on very well. After a time they sent word the serjeant was very ill. (1750s)

The use of these verbs with the function of 'to encourage or persuade a person to do something or proceed with a course of action' (OED) is not new in that the imperative form is frequently used from the 16 th century onwards, as in (21) and (22):

(21) Yet be not thou dismaid, go on, and bolden well thy selfe. (OED-1566)

(22) Go on, then, I say; banish the occupants or owners, or kill them,...and take their land and property as spoil.(OED1844)

Moreover, as is the case in PDE, this verb was associated with the meaning of 'to continue, persevere, or persist in doing something, or in making, dealing with, or using something' (OED), as in (23):
(23) If you go on to learn at this rate, you will soon puzzle me, in Greek especially. (OED-1739)

To come on, on the other hand, is always used with the idiomatic meaning of 'to start', as in (24) and (25), and it is not affected by significant changes. In fact, in the majority of the cases it denotes an activity or an event with an ingressive meaning as can be found in PDE:

(24) I know nothing of the robbery; $m y$ trial came on so soon, I could send for none of my friends; I am innocent. (1770s)

(25)Why is not he here? - A. He did not know that the trial would come on tonight; I saw some of the things at the watchhouse. (1790s)

Two examples that make a case for the emergence of the aspectual connotation of on are to pass on and to move on, which underwent a process of grammaticalization that caused the decategorialization of the preposition to an adverbial particle status, the reanalysis of the items within the clause and the consequent fusion of the nonverbal element with the verb from a phonological point of view. As a consequence, on in addition to being used as a preposition in the pattern V+PP started to occur, displaying an increasing boundedness with the preceding verb and showing a change in its linguistic features. In fact, when on performs as an adverbial particle, it tended to lead to the phonological reduction of the verb through a process involving coalescence and started to be used without any other following NP. Thus it occurred as a preposition followed by a NP, as in (26), but also as an adverbial particle characterized by an aspectual 
meaning of continuity and duration, as in (27)-(28):

(26) What passed on the subject of inlisting? - Harris talked of going for a soldier. (1770s)

(27) I did not speak to them, but looked at them very hard - they passed on, and I soon afterwards heard a scream. (1830s)

(28) Here, "Bill, take it" he said it was not him, it was someone who had passed on. (1830s)

More specifically, the occurrence of on as a preposition, as in (26), followed by a NP, i.e. the subject of inlisting, was set in rivalry with other cases characterized by a reduction in autonomy and by an increase in cohesion with the preceding verb. Specifically, in considering (26), to pass has the meaning of 'to spend time doing something' (MacmillanOnline) whereas the non-verbal element introduces the states which the verb refers to.

Instead, in (27) and (28), on displays the function of a particle and it contributes to the meaning of the whole $\mathrm{V}+$ particle combination to pass on, and it is used with the meaning of 'to move from one activity to another' (Cowie and Mackin, 1975). This means that on does not show autonomy within the clause and that it forms a single lexical item with the preceding verb to pass. In this regard, the fact that the verb to pass on behaving as a unit first appears from the 1800 onwards is indicative of the ongoing structural and semantic change that on underwent over the centuries and that led it to the acquisition of an aspectual force.

Moreover, these considerations are particularly important in that they confirm what other scholars state with reference to other periods in the history of English, among others Claridge (2000, p. 342; cf. Elenbaas, 2007, pp. 215-219) who describes the multiword verbs in EME and explains that the emergence of the aspectual particles underwent semantic reanalysis and came through the specific meaning of motion and direction to denote aspectual meaning. In fact, the preposition on firstly appeared with verbs expressing the connotation of 'motion through space and time', as in (26), and then acquired another status, that of a particle, and an aspectual force, as in (27) and (28). In particular, the particle on came to indicate a durative aspect (Brinton, 1988, p. 113).
A similar trend can be observed with regard to the verb to move on, as represented in the following examples:

(29) We did not think proper to lend any money upon it; I seeing the name on the bottom, bid her carry it to the right owner; I went to see for Mr. Cole, and found he was moved. (1750s)

(30) I saw him on the following morning; he was then moved down to a better apartment. (1770s)

(31) I had no particular reason for not going on indeed, we were moving on slowly I did not say. (1830s)

(32) he certainly should not run away, in a very temperate tone we moved on. I was moving on when the blow was struck. (1830s)

At the beginning of the 1750 s the verb to move was used only as a single lexical verb denoting the taking of action or the change in the position of something or somebody, as in (29), or followed by a complex preposition, as in (30). In the $1830 \mathrm{~s}$, instead, the verb to move was followed by on functionally behaving as a particle, as in (31) and (32), in addition to its prototypical use as a single lexical verb still frequent in PDE. For example, in the case of (31), the verb to move on shows the literal meaning of 'to progress, to move along' (Macmillan) and the particle adds the aspectual meaning of duration and continuity to the verb. In particular, the whole verb+particle construction is used with idiomatic meaning and specifically with the meaning of 'to leave a place when somebody in authority tells you' (MacmillanOnline).

\section{Conclusion}

The aim of the present paper has been to investigate the development of the aspectual and idiomatic properties of the PVs containing the particle on in Late Modern Spoken English.

Despite aspectual PVs containing the particle on not being very frequent in the data, they nevertheless suggest important elements in the comprehension of the establishment of aspectual particles in the LModE period. The particle on, in general, possesses a relative stability in use which reaches a peak in the 1830s, having experienced a decline in the previous two decades. The fact that transitive verbs are constantly used across the decades, whereas intransitive patterns steadily 
increased in popularity, acquires relevance in so far as the use of the aspectual on is favoured in the intransitive verbs.

From a semantic perspective, what is worth noting is the establishment of new PVs. In this case, the emergence of new forms can be connected with a process of change that led a specific item to the acquisition of an aspectual meaning, along with the well-established meaning of motion and direction.

The study also reveals that many PVs underwent an extension in use and developed innovative meanings, despite being characterized by a relative stability in their syntactic features.

Factors that appear more relevant are:

- Relative stability in the use of PVs in the time span 1750-1850;

- A general shift from spatial to aspectual meaning in intransitive verbs, between losses and gains;
- An extension in the meaning of transitive verbs.

The findings demonstrate that the LModE era was characterized by the emergence of aspectual meanings and by the gradual increase in the idiomaticity of the V+particle combinations. This means that during the LModE era, PVs continued to evolve following the path attested in previous stages (Denison, 1981; Hiltunen, 1983; Elenbaas, 2007).

The results reached so far underline the necessity of further research on this topic by extending the area of investigation to other particles, firstly along and away. The aim will be to investigate the major and most significant changes and explain in detail the diachronic processes involved.

\section{Acknowledgements}

I would like to express my gratitude to my supervisor Professor Rita Calabrese for her support and encouragement.

\section{References}

AARTS, B., 1989. Verb-preposition constructions and small clauses in English. Journal of Linguistics, vol. 25, no. 2, pp. 277-290.

BIBER, D., CONRAD, S. and REPPEN, R., 1998. Corpus linguistics. Investigating language structure and use. Cambridge: Cambridge University Press.

BIBER, D., JOHANSSON, S., LEECH, G., CONRAD, S. and FINEGAN, E., 1999. Longman grammar of spoken and written English. Harlow: Pearson Education Limited.

BICK, E., 2001. The VISL System: Research and applicative aspects of IT-based learning. Paper presented at NoDaLiDa 2001, Uppsala, Sweden, May 21-22. [online] [Accessed 15 April 2014] Available at: http://www.visl.sdu.dk/ eckhard/pdf/NoDaLiDa2001.ps.pdf

BOLINGER, D., 1971. The phrasal verb in English. Cambridge, MA: Harvard University Press.

BRINTON, L. J. and AKIMOTO, M., 1999. Introduction. In: L.J. Brinton and M. Akimoto, eds. Collocational and idiomatic aspects of composite predicates in the history of English. Amsterdam and Philadelphia: John Benjamins Publishing Co, pp. 1-20.

BRINTON, L. J. and TRAUGOTT, E. C., 2005. Lexicalization and language change. Cambridge: Cambridge University Press.

BRINTON, L. J., 1988. The development of English aspectual systems. Aspectualizers and postverbal particles. Cambridge: Cambridge University Press.

CAPPELLE, B., 2005. Particle patterns in English. A comprehensive coverage. Leuven: Katholieke Universiteit Leuven PhD Dissertation. [online] [Accessed 05 August 2015] Available at: https://lirias.kuleuven.be/bitstream/123456789/111279/1/Entire

CLARIDGE, C. 2000. Multi-word verbs in Early Modern English. A corpus-based study. Amsterdam and Atlanta: Rodopi.

Collins COBUILD Dictionary of phrasal verbs. 2011 . London: Harper Collins.

COWIE, A.P. and MACKIN, R., 1975. Oxford Dictionary of current idiomatic English. Volume 1: Verbs with prepositions \& particles. Oxford and London: Oxford University Press.

CRYSTAL, D., 2010. The Cambridge encyclopedia of the English language, 2nd edn. Cambridge: Cambridge University Press.

CULPEPER, J. and KYTÖ, M., 2010. Early Modern English dialogues: Spoken interaction as writing. Cambridge and New York: Cambridge University Press.

CURME, G.O.1931. Syntax. New York: D. C. Heath.

DEHÉ, N., 2002. Particle verbs in English. Syntax, information structure and intonation. Amsterdam and Philadelphia: John Benjamins Publishing. 
DENISON, D., 1981. Aspects of the history of English group-verbs: With particular attention to the syntax of the Ormulum. Oxford: University of Oxford PhD Dissertation. [online] [Accessed 8 January 2016] Available at: https://www.escholar.manchester.ac.uk/uk-ac-man-scw: 74782 ELENBAAS, M.B., 2007. The synchronic and diachronic syntax of the English verb-particle combination. Utrecht: LOT.

FRASER, B., 1974. The verb-particle combination in English. Tokyo: Taishukan Publishing Company.

HEFFER, C., 2005. The language of jury trial. A corpus-aided analysis of legal-lay discourse. New York: Palgrave Macmillan.

HILTUNEN, R., 1983. The decline of the prefixes and the beginning of the English phrasal verb: The evidence from some Old and early Middle English texts. Turku: Turun Yliopisto.

HILTUNEN, R., 1999. Verbal phrases and phrasal verbs in Early Modern English. In: L. J. Brinton and M. Akimoto, eds. Collocational and idiomatic aspects of composite predicates in the history of English. Amsterdam and Philadelphia: John Benjamins Publishing Company, pp. 133-165. HOPPER, P. J. and TRAUGOTT. E.C., 2003. Grammaticalization, 2nd edn. Cambridge: Cambridge University Press.

HUBER, M., 2007. The Old Bailey Proceedings, 1674-1834: Evaluating and annotating a corpus of 18th- and 19th-century spoken English. In A. Meurman-Solin and A. Nurmi, eds. Annotating variation and change. [online] [Accessed 16 January 2012] Available at: http://www.helsinki.fi/varieng/series/volume/01/huber

HUBER, M., NISSEL, M., MAIWALD, P. and WIDLITZKI, B. 2012. The Old Bailey Corpus. Spoken English in the 18th and 19th centuries. [online] [Accessed 14 March 2016] Available at http://www1 .uni-giessen.de/oldbaileycorpus

HUDDLESTON, R. and PULLUM, G.K., 2002. The Cambridge grammar of the English language. Cambridge: Cambridge University Press.

KARLSSON, F., 1995. Designing a parser for unrestricted text. In: F. Karlsson, A. Voutilainen, J. Heikkilä and A. Anttila, eds. Constraint Grammar: A language-independent framework for parsing unrestricted text. Berlin and New York: Mouton de Gruyter, pp. 1-40.

KENNEDY, A. G., 1920. The modern English verb-adverb combination. Stanford: Stanford University Press.

LIPKA, L., 1972. Semantic structure and word-formation: Verb-particle constructions in contemporary English. München: Wilhelm Fink Verlag.

LIVE, A. H., 1965. The discontinuous verb in English. Word, vol. 21, no.3, pp. 428-451.

Macmillan dictionary (online). http://www.macmillandictionary.com

Macmillan phrasal verbs plus dictionary. 2005. Oxford: Macmillan Publishers.

OED. Oxford English Dictionary. http://www.oed.com

POUTSMA, H., 1926. A grammar of Late Modern English. Part II: Parts of speech. Section II: The verb and the particles. Groningen: P. Noordhoff.

QUIRK, R., GREENBAUM, S., LEECH G. and SVARTVIK, J., 1985. A comprehensive grammar of the English language. London: Longman.

RODRÍGUEZ-PUENTE, P., 2012. The Development of non-compositional meanings in phrasal verbs. A corpus-based study. English Studies, vol. 93, no.1, pp. 71-90.

RODRÍGUEZ-PUENTE, P., 2013. The development of phrasal verbs in British English from 1650 to 1990: A corpus-based study. University of Santiago de Compostela PhD Dissertation. Unpublished thesis.

RYDÉN, M., 1998. The study of eighteenth century English syntax. In: M. Rydén, I. TiekenBoon van Ostade and M. Kytö, eds. A reader in Early Modern English. Frankfurt am Main: Peter Lang, pp. 221-230.

SPASOV, D., 1966. English phrasal verbs. Sofia: Naouka i Izkoustvo.

THIM, S., 2012. Phrasal verbs. The English verb-particle construction and its history. Berlin and Boston: De Gruyter Mouton.

TIEKEN-BOON VAN OSTADE, I., 2009. An Introduction to Late Modern English. Edinburgh: Edinburgh University Press.

WILD, C., 2010. Attitudes towards English usage in the Late Modern period: The case of phrasal verbs. University of Glasgow PhD Dissertation. [online] [Accessed 06 April 2016] Available at: http://www.theses.gla.ac.uk/2264

WILLIAMS, C., 2013. Changes in the verb phrase legislative language in English. In: B. Aarts, J. Close, G. Leech and S. Wallis, eds. The verb phrase in English. Investigating recent language change with corpora. Cambridge, UK: Cambridge University Press, pp. 353-371. 
Relevant websites

http://www.oldbaileyonline.org/

http://www.macmillandictionary.com/

http://www1 .unigiessen.de/oldbaileycorpus

http://www.beta.visl.sdu.dk/

http://www.oed.com

Author's address and contact details

Ljubica Leone

Department of Humanities

University of Salerno

Italy

E-mail: ljubical@libero.it 